\title{
Identifying and capturing energy savings in an integral motor-drive system
}

\author{
M. Ektesabi ${ }^{1} \&$ H. Felic ${ }^{2}$ \\ ${ }^{I}$ Robotics and Mechatronics, Faculty of Engineering and Industrial \\ Sciences, Swinburne University of Technology, Australia \\ ${ }^{2} C M G$ Technology, Australia
}

\begin{abstract}
Optimising industrial motor driven applications, when coupled with best practice motor management, can deliver more than 57\% energy savings. The need for variable speed drives and their advantages are very well known, but unfortunately, the integration of the knowledge of efficient electrical motors and advantages of power electronics engineering is not well practiced by industries. It has also been observed that further saving can be achieved by integration of efficient systems. In this paper, a compact integral motor-drive unit built to operate in arduous industrial environments with optimised power consumption and best practice motor management under different load conditions is proposed. Reduction of the losses in the system provides higher efficiency and further savings to overcome heat without requirement of any additional cooling system. The critical issues such as space limitations within the existing spatial dimensions of motor, management of heat transfer from the motor to the sensitive drive control unit, management of vibration transfer to the sensitive drive control unit, management of electromagnetic interference within the unit and externally, management of other environmental effects on the sensitive drive control unit have been considered and discussed in this paper.
\end{abstract}

Keywords: electromagnetic interference, energy saving, integral motor, motor management, sensitive electronics.

\section{Introduction}

Today, electric motors and controllers are essential parts of most equipment. The current engineering design practice is based on viewing the motors and their 
controllers as separate components leading to a number of design limitations both in terms of space and functionality. Most scholars who endeavour to improve motor system energy efficiency have focused on the motor, rather than other individual motor-driven system components or, more importantly, on the system as a whole. To rectify this situation, it is deemed necessary to integrate those parts as one unit. Variable speed drives (VSDs) are considered as one of the most important tools for motor management and energy saving. Migration from traditional motors to more intelligent motors may be seen as a new motor manufacturing trend towards addition of intelligence to the motors, so that the overall package requires no more space, yet is capable of increase in efficiency and working capabilities. This is achievable due to availability of higher performance compact semiconductors, and use of them as the integral part of the motor drive system called integral motor. In last decade, many of such systems have been produced which are now replacing the other types of low power controlled motors.

In this paper, the energy saving techniques associated with energy efficient motors and their controllers are discussed and the improvement on energy saving features by integration is presented. A novel integral motor which is an integrated asynchronous motor-frequency controller package for variable speed applications is proposed. Integration in this case, also means a compact, reliable, cost efficient system, which is easy to install for replacement of conventional systems.

The proposed motor with a unique development brings intrinsic powerful yet simple speed control of electric motors to the hand of the user. State-of-the art control technology incorporated into a normal sized motor allows a user to plug the motor into a standard supply and use it straight away with no additional installation. The compact integral motor offers significant startup and ongoing cost savings. The proposed Motor is the first truly integrated motor-drive unit with a design, which overcomes heat, vibration and electromagnetic interference which are damaging to sensitive electronics.

In the next sections, the information leading to identify and capture higher energy efficient systems are presented which in turn justifies the advantages of the proposed integral motor.

\subsection{Energy efficient motors and energy saving}

A large portion of the cost of electricity for manufacturing is associated with pumps, fan, blower systems, and air compression (figure 1). Industry consumes high share of electricity to operate motor-driven systems. With an improvement in energy saving systems, the potential savings are very large - over 100 billion $\mathrm{KWh}$ /year energy savings and billions of annual energy cost savings opportunity with existing and new technology [3].

System improvement opportunities in many cases may include: improved sizing and proper matching to load, use of more efficient drive trains, improved system layout, updated and well-maintained controls, improved operation and maintenance, and use of variable speed drives (VSDs) [4]. 


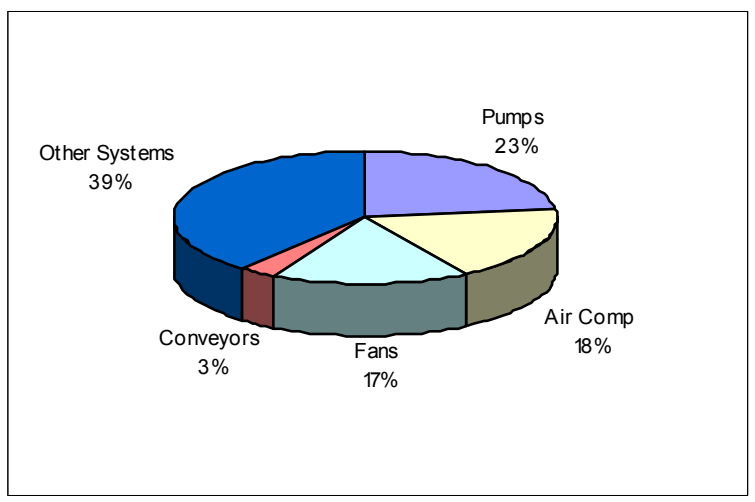

Figure 1: Energy consumption in industrial sector.

In pump and fan applications, the power consumed is proportional to the operating speed cubed. Efficiencies of pumps and fans vary greatly and depend on operational requirements. Fine-tuning the system can have a big impact on energy consumption. Although pump (or fan) and other systems are separate entities, they are totally dependent on each other. Changing one will have a significant impact on the performance of the other [5].

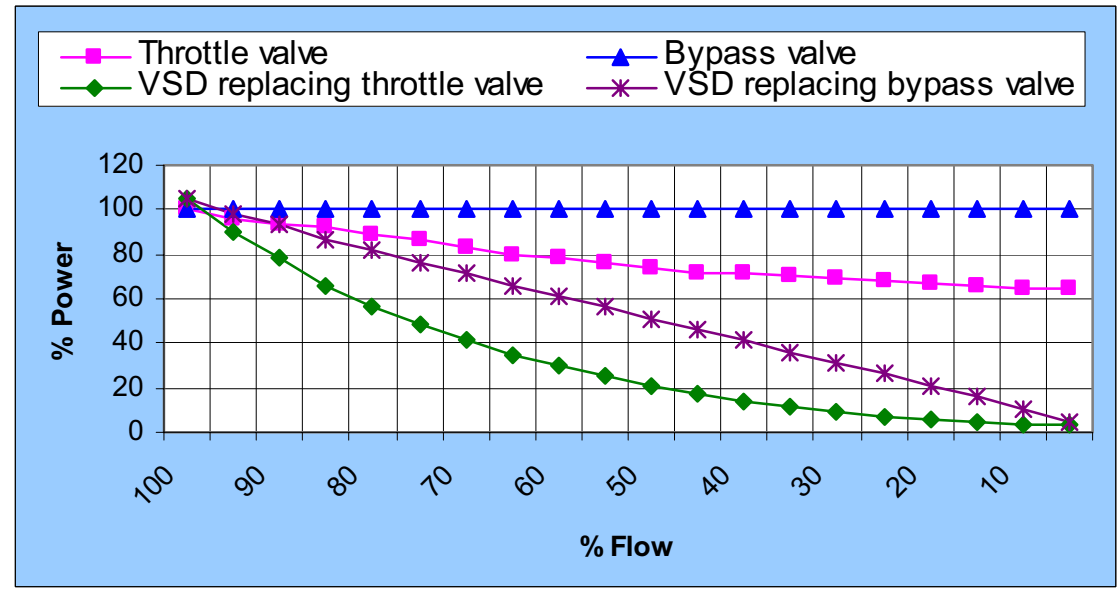

Figure 2: $\quad$ Percentage of power consumption in pump with different control options.

\subsection{Control options}

The most basic form of control is to manage flow by adding friction at the pump or fan outlet. For pumps, this is achieved by a throttle valve. For fans it is done with a damper. It is effective, but inefficient. Most industrial systems have 
pumping requirements with several operating points or variable flow and pressure requirements. Picking the pump (fan) with the optimum efficiency for a specific delivery is only part of the story. The other part is controlling the flow rate to match the process requirements. The most efficient control option is by use of the VSD which most closely matches the ideal pump curve, which is shown in figure 2.

\subsection{Motor performance}

To make a contribution on energy saving using the integral motor it is worth considering the efficiency of motors. Table 1 shows the performance of 5 model motors in which the stack length and construction design of the motors make each of them suitable for different loads at different conditions. The optimum voltage for best efficiency in each case indicates the performance of each system. To consider any of the above models it is necessary to know the type of applications and integrate the motor with e best possible drive setting suitable for the application.

Table 1: $\quad$ Motor performance.

\begin{tabular}{|c|c|c|c|c|c|}
\hline Motor & M1 & M2 & M3 & M4 & M5 \\
\hline $\begin{array}{c}\text { Designed } \\
\text { RPM }\end{array}$ & 1430 & 1431 & 1443 & 1447 & 1446 \\
\hline Stack Length & $100 \mathrm{~mm}$ & $100 \mathrm{~mm}$ & $125 \mathrm{~mm}$ & $35 \mathrm{~mm}$ & $55 \mathrm{~mm}$ \\
\hline $\begin{array}{c}\text { Rated Output } \\
{[\mathrm{kW}]}\end{array}$ & $\begin{array}{c}1.5 \mathrm{KW} @ \\
(240 \mathrm{~V}, 50 \mathrm{~Hz})\end{array}$ & $\begin{array}{c}1.1 \mathrm{KW} @ \\
(120 \mathrm{~V}, 50 \mathrm{~Hz})\end{array}$ & $\begin{array}{c}1.5 \mathrm{KW} @ \\
(240 \mathrm{~V}, 50 \mathrm{~Hz})\end{array}$ & $\begin{array}{c}0.37 \mathrm{KW} @ \\
(240 \mathrm{~V}, 50 \mathrm{~Hz})\end{array}$ & $\begin{array}{c}0.75 \mathrm{KW} @ \\
(240 \mathrm{~V}, 60 \mathrm{~Hz})\end{array}$ \\
\hline No Load Current & $3.708 \mathrm{~A}$ & $4.584 \mathrm{~A}$ & $3.9492 \mathrm{~A}$ & $1.3019 \mathrm{~A}$ & $2.55 \mathrm{~A}$ \\
\hline No Load Input & $190 \mathrm{~W}$ & $110 \mathrm{~W}$ & $177.6 \mathrm{~W}$ & $86.4 \mathrm{~W}$ & $137.2 \mathrm{~W}$ \\
\hline Full Load phase & $5.73 \mathrm{~A}$ & $8.2 \mathrm{~A}$ & $5.95 \mathrm{~A}$ & $1.72 \mathrm{~A}$ & $3.4 \mathrm{~A}$ \\
\hline $\begin{array}{c}\text { Full Load } \\
\text { RPM }\end{array}$ & 1413 & 1417 & 1432 & 1427 & 1735 \\
\hline Full Load \% eff. & $80.7 \%$ & $80 \% \mathrm{~A}$ & $82 \%$ & $74.4 \%$ & $78 \%$ \\
\hline Full Load P F & 0.78 & 0.81 & 0.74 & 0.70 & 0.69 \\
\hline $\begin{array}{c}\text { Wind Temp rise } \\
93.4^{\circ} \mathrm{K}\end{array}$ & $62^{\circ} \mathrm{K}$ & $76^{\circ} \mathrm{K}$ & $45^{\circ} \mathrm{K}$ & $53^{\circ} \mathrm{K}$ \\
\hline $\begin{array}{c}\text { Voltage for best } \\
\text { efficiency }\end{array}$ & $240 \mathrm{~V}$ & $130 \mathrm{~V}$ & $240 \mathrm{~V}$ & $220-230 \mathrm{~V}$ & $230-240 \mathrm{~V}$ \\
\hline
\end{tabular}

\subsection{Effect of power supply}

As compared with the standard power supply, the reactive smooth type power supply (for example, isolation transformer and generators) minimises the high frequency noise/harmonics from the input rectifier of the drive system and effects on the measurement and the performance of the system. It affects the peak charging current, minimises the ripple current, which in turn affects the DC link voltage value. The reduction of the mean DC link voltage in this case demands higher motor current from the inverter for the same power output, which in turn causes the higher slip and higher winding temperature rise in the 
motor which contributes to lower efficiency. Tables 2 and 3, show the effect of the type of power supply on the motor drive system performance.

Table 2: $\quad$ Effect of power supply on Motor M3 +VSD.

\begin{tabular}{|c|c|c|}
\hline $\begin{array}{c}\text { Motor M3 } \\
\text { Tested with VSD } \\
\text { at } 1.5 \mathrm{~kW} / 60 \mathrm{~Hz} \text { (output) }\end{array}$ & $\begin{array}{c}\text { Setting 1 } \\
\text { Generator and isolation } \\
\text { transformer Supply } \\
(240 \mathrm{~V}, 50 \mathrm{~Hz})\end{array}$ & $\begin{array}{c}\text { Setting 2 } \\
\text { Standard Main } \\
\text { Input supply } \\
(240 \mathrm{~V}, 50 \mathrm{~Hz})\end{array}$ \\
\hline F.L. RPM & 1654 & 1690 \\
\hline F.L. eff [\%] & $73.9 \%$ & $76.4 \%$ \\
\hline power factor & 0.80 & 0.62 \\
\hline Wind Temp Rise & $93^{\circ}$ & $76.4^{\circ}$ \\
\hline Body Temp rise & $78^{\circ}$ & $53^{\circ}$ \\
\hline
\end{tabular}

Table 3: $\quad$ Effect of power supply on Motor M1 +VSD.

\begin{tabular}{|c|c|c|}
\hline $\begin{array}{c}\text { Motor M1 } \\
\text { Tested with VSD } \\
\text { at } 1.1 \mathrm{~kW} / 52.5 \mathrm{~Hz} \text { (output) }\end{array}$ & $\begin{array}{c}\text { Setting 1 } \\
\text { Generator and isolation } \\
\text { transformer Supply } \\
(240 \mathrm{~V}, 50 \mathrm{~Hz})\end{array}$ & $\begin{array}{c}\text { Setting 2 } \\
\text { Standard Main } \\
\text { Input Supply } \\
(240 \mathrm{~V}, 50 \mathrm{~Hz})\end{array}$ \\
\hline F.L. RPM & 1475 & 1502 \\
\hline F.L. eff [\%] & $76.6 \%$ & 77.1 \\
\hline power factor & 0.795 & 0.58 \\
\hline Wind Temp Rise & $73^{\circ}$ & $64.6^{\circ}$ \\
\hline Body Temp rise & $53^{\circ}$ & $45.3^{\circ}$ \\
\hline
\end{tabular}

\subsection{Effect of drive systems and settings}

VSDs from different manufacturers have different settings and efficiencies. Four of these VSDs have been selected and tested based on their ratings. As expected they show differences in performance and efficiency. Table 4, shows the differences. Hence for energy efficient systems it is important to have the most efficient VSD system with right settings.

Table 4: $\quad$ Performance and efficiency of different VSDs.

\begin{tabular}{|c|c|c|c|c|c|c|c|c|c|c|}
\hline VSD & $\begin{array}{c}\text { Supply } \\
\text { Voltage }\end{array}$ & $\begin{array}{c}\text { Supply } \\
\text { Hz }\end{array}$ & $\begin{array}{c}\text { Supply } \\
\text { (Amps) }\end{array}$ & $\begin{array}{c}\text { Input } \\
\text { (Watts) }\end{array}$ & $\begin{array}{c}\text { Motor } \\
\text { Volts }\end{array}$ & $\begin{array}{c}\text { Motor } \\
\text { Hz }\end{array}$ & $\begin{array}{c}\text { Motor } \\
\text { A }\end{array}$ & RPM & $\begin{array}{c}\text { Output } \\
\text { (W) }\end{array}$ & $\begin{array}{c}\text { \%Eff- } \\
\text { Overall }\end{array}$ \\
\hline 1 & 240 & 50 & 11 & 2127 & 218 & 50 & 7.8 & 1314 & 1484 & 69.77 \\
\hline 2 & 240 & 50 & 11.4 & 2200 & 217 & 50 & 7.3 & 1375 & 1501 & 68.23 \\
\hline 3 & 240 & 50 & 10.5 & 2007 & 208 & 50 & 6.5 & 1370 & 1500 & 74.74 \\
\hline 4 & 240 & 50 & 10.4 & 2011 & 230 & 50 & 6.3 & 1387 & 1500 & 74.56 \\
\hline
\end{tabular}




\section{Proposed integral motor}

From the last sections we can conclude that energy saving systems should have following key factors and efficient sub-systems such as, motor selection, power quality, motor controller (VSDs), transmission, end-use device (e.g. pump, fan, etc), system and design, type of process, and maintenance practices.

For the same power system, the combination of an efficient VSD and a more efficient motor and avoiding all the other losses in the motor drive system will lead to a better energy saving system. The proposed Integral Motor optimizes the Motor drive system to higher level. The selected motor suits the drive system keeping in mind the optimum voltage for best efficiency and other critical parameter $\mathrm{s}$ of above tables. The proposed system is a dedicated system for a particular end user (e.g. pump, fan, etc.) with a preset program for the best matching with the type of process or load characteristics.

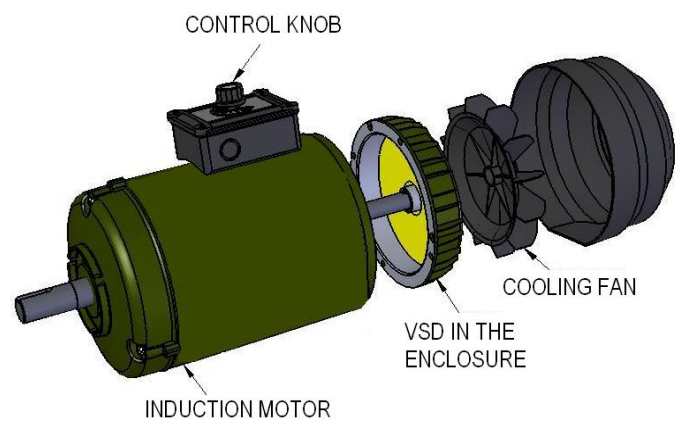

Figure 3: $\quad$ Proposed integral motor.

Figure 3 shows the construction of the integral motor. In this system by use of efficient systems, better design and reduction of the losses in the drive and motor, it was possible to avoid external cooling fans. The system operates satisfactorily in the speed range without necessity of any external cooling systems, which in turn is a saving in motor construction as well as in energy.

In figure 4 , the proposed system has been compared with the conventional motor-drive system. This system shows the immediate advantages, such as compactness, and savings in system cost. It has a lower installation cost and is more efficient as the losses in the transmission systems are minimised.

The high switching frequencies of VSD generate conducted and radiated noise, and additionally they may cause significant damage to the motor and the embedded systems by producing bearing currents and insulation voltage stress. By integration it is easier to do the grounding, which reduces the bearing current effect. The effect of insulation voltage stress particularly increases and has more serious effect if the length of cable between the VSD and motor increases. This is minimised in the proposed integral motor (Figures 3 and 4). 


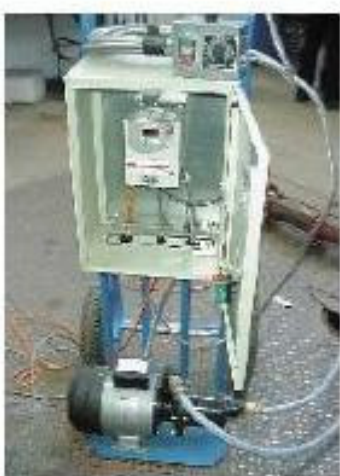

Conventional System

+ Motor + VVVF Drive

+ Control Box + Protection Cabinet

+ Wires and Cables + Installation

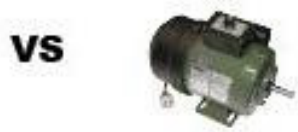

Proposed System

Figure 4: $\quad$ Proposed system vs conventional system.

Current harmonics in the VSD input stage can also feed back into the power bus grid, and can disrupt other types of equipment [6]. Harmonics can also cause supplementary losses and temperature-rise of all the elements in the supply system. These high frequencies can produce electromagnetic interference (EMI) both as high frequency airborne radiated interference mostly in the inverter to motor cable, as well as the conducted noise in the supply cables. The proposed integral motor with in built common mode filter and a closed metallic shielding provides a better control of conducted as well as radiated EMI.

As is shown in Figure 3, a traditional end shield was used to shield the heat, along with an epoxy material used to pot the electronics in their enclosure. The electronic enclosure was also design as a heat sink for electronic components and is finned for further heat dissipation. Damaging vibration was countered by the absorptive properties of the same epoxy resin. Increased rigidity to the overall system was another benefit provided by the potting against vibration.

\subsection{System performance}

The Integral motor tested on a pump application and the experimental results were compared with other Motor Drive systems as well as the conventional pump controller using cycle control in conjunction with throttle system. It was observed that, Using VSD with standard motors and standard system saves about $30 \%$ in the energy consumption and increase in overall efficiency by $15 \%$. And by use of more efficient pump driven by an integrated efficient motor drive system there can be increase in efficiency and about $57 \%$ saving in the energy (shown in figure 5). 


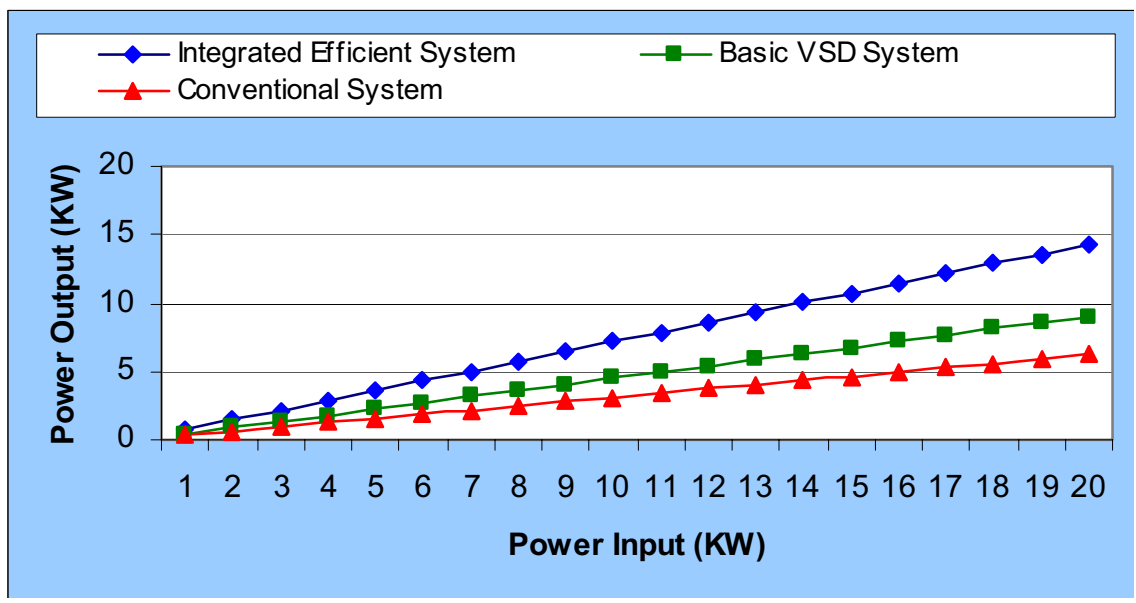

Figure 5: Higher output power for higher quality system.

\section{Conclusion}

In this paper a new-generation integral motor-drive has been demonstrated. It proposes a compact unit built to operate in arduous industrial environments with optimized power consumption and best practice motor management under different load conditions. Advantages of the proposed Integral motor are compactness of combo motor and drive system with no external cabling/wiring. The motor provides a perfect shielding for least amount of radiated emission. It has an inbuilt filter for EMC compliance. It has been designed to provide lower EMC noise for immunity of the internal electronics as well as other neighboring systems. It can be a standalone system for the best load/application performance with no commissioning and programming. It is an integrated motor-drive unit with a design to overcome heat, vibration and electromagnetic interference, which are damaging to sensitive electronics without requirement of any additional cooling system.

It was demonstrated that higher efficiency of the proposed systems will lead to an increase in efficiency and about 57\% saving in the energy. In this way the higher efficient system not only leads to electricity savings, but also to similar demand savings.

\section{References}

[1] ABB LV Motors/Cat/Bu/General Purpose motors/integral GB 09-2003.

[2] NORDAC trio, "SK300E frequency inverter, Motor, Speed Reducer", Nord Gear Corporation, 2003 (http://www.nord.com/manuals/files/bwF3031_US.pdf

[3] European Commission Conference: 'Energy Efficiency Improvements in Motors and Drives"; October 29-31, 1996; Portugal 
[3] European Commission Conference: 'Energy Efficiency Improvements in Motors and Drives"; October 29-31, 1996; Portugal

[4] Energy Using Product (EuP) Directive Preparatory Study; Lot 11: Motors Analysis of existing technical and market information First Stakeholder Meeting; DG TREN, Brussels, June 292006

[5] Australian Greenhouse Office, Department of the Environment and Heritage, http://www.greenhouse.gov.au/motors

[6] Sidney Bell, Timithy J. Cookson, Steven A. Cope, Richard A. Epperly, Annika Fischer, David W. Schegel, and Gary L. Skibinski," Experience With Variable-Frequency Drives and Motor Bearing Reliability", IEEE Transactions On Industry Applications, Vol 37, No.5, September/October 2001 . 